\title{
30 ANOS DA ABORDAGEM TRIANGULAR: CONTRIBUIÇÕES DOS DOCENTES DE ARTE DO MUNICÍPIO DE TERESÓPOLIS-RJ
}

\section{YEARS OF THE TRIANGULAR APPROACH: CONTRIBUTIONS OF THE ART TEACHERS IN TERESÓPOLIS CITY-RJ}

\author{
SILVA, Maria Gabriela da ${ }^{1}$ \\ CARMO, Ana Carolina Rigoni ${ }^{2}$
}

\begin{abstract}
RESUMO
Este artigo apresenta alguns aspectos da pesquisa "Ensino de Arte: Considerações sobre a prática da Abordagem Triangular no município de Teresópolis-RJ" realizada no Mestrado Profissional em Práticas de Educação Básica (MPPEB) no Colégio Pedro II, entre 2018 e 2020. O objetivo foi pesquisar a aplicabilidade da Abordagem Triangular nas salas de aulas por meio da ótica de professores de Arte efetivos da Rede Pública Municipal de Teresópolis-RJ, abarcando suas interpretações, delineando potencialidades e limitações de seu uso no chão da escola e considerando as quatro linguagens artísticas como mediadoras de seus pressupostos teóricopráticos.
\end{abstract}

Palavras-Chave: Abordagem triangular; Ensino de arte; Prática docente; Ana Mae Barbosa; Teresópolis-RJ.

\begin{abstract}
This paper presents some aspects of the research "Teaching Art: Considerations on the practice of the Triangular Approach in the city of Teresópolis-RJ" carried out in the Professional Master in Basic Education Practices (MPPEB) at Colégio Pedro II, between 2018 and 2020. The aim was to research the applicability of the Triangular Approach in classrooms through the perspective of effective Art teachers who work in the Teresópolis-RJ public schools, encompassing their interpretations, outlining the potential and limitations of their use on the school floor and considering the four artistic languages as mediators of their theoretical-practical statements.
\end{abstract}

1 Colégio Pedro II - CPII / Mestrado Profissional em Práticas de Educação Básica - MPPEB. Rio de Janeiro, RJ, Brasil. Secretaria Municipal de Educação de Teresópolis - RJ. Teresópolis, RJ, Brasil. ORCID: http://orcid.org/0000-0003-2877-0472 e-mail: mariagabriela.artes@gmail.com

2 Colégio Pedro II - CPII / Mestrado Profissional em Práticas de Educação Básica - MPPEB e Mestrado Profissional em Educação Profissional e Tecnológica - ProfEpt. Rio de Janeiro, RJ, Brasil. ORCID: https://orcid.org/0000-0002-6989-4028 e-mail: anacarolinarigoni@gmail.com

30 ANOS DA ABORDAGEM TRIANGULAR: CONTRIBUIÇÕES DOS DOCENTES DE ARTE DO 
DOI: $10.12957 /$ e-mosaicos.2021.53751

KeYwORDS: Triangular Approach; Art teaching; Teaching practice; Ana Mae Barbosa; TeresópolisRJ.

\section{INTRODUÇÃO}

Em 2021, a primeira edição do livro "A Imagem no Ensino da Arte - anos oitenta e novos tempos" completa trinta anos. Nesta obra clássica, Ana Mae Barbosa apresentou ao grande público sua concepção de ensino de Arte por meio da triangulação de ações de leitura, contextualização e fazer artístico, conhecida por Abordagem Triangular.

Após três décadas, qual importância teria para o mundo acadêmico e para a escola realizar uma pesquisa sobre esta teoria e sua aplicação prática? A resposta vem das salas de aulas, local de ressignificações desta diretriz pedagógica na contemporaneidade, que mantém destacada importância e aplicabilidade nas aulas de Arte.

A inserção da imagem no ensino da Arte como meio para promover a alfabetização visual crítica discente foi a bandeira defendida por Ana Mae Barbosa ao propor a Abordagem Triangular, em tempos onde o ensino artístico nas escolas primava a liberdade de criação espontânea e individual do aluno, sem the apresentar conteúdos ou informações adicionais sobre o que era produzido. A intenção era deixar fazer, apenas. Foi justamente ao contrapor essa visão de ensino parcial, baseada somente na produção artística, que Barbosa propôs a triangulação "ler, contextualizar e fazer", externando a necessidade da leitura visual e sua contextualização a este fazer, numa teia de aspectos interligados. Para a autora, o fazer (sozinho) não preparava o aluno para uma experiência epistemológica em Arte. Era necessário ampliar a experimentação à decodificação da informação visual.

A Abordagem Triangular foi sistematizada e experimentada por Ana Mae Barbosa e colaboradores durante os anos oitenta, tendo como palcos importantes dessa experiência o XIV Festival de Inverno de Campos de Jordão-SP, em 1983, e o Museu de Arte Contemporânea da Universidade de São Paulo (MAC-USP), entre 1987 e 1993.

Chegou às escolas por intermédio de palestras e cursos que Ana Mae Barbosa ministrou a professores ao longo dos anos oitenta e noventa, mas, sobretudo, devido à publicação do livro "A imagem no ensino da Arte: anos oitenta e novos tempos", em 1991. O capítulo denominado "A Importância da Imagem no Ensino da Arte: diferentes metodologias" apresentou aos leitores os conceitos sobre a Abordagem Triangular e sua importância para o ensino democrático da Arte no Brasil.

Antecipando o marco de 30 anos da primeira edição do livro que a projetou em larga escala, a pesquisa brevemente relatada neste artigo pretendeu ao mesmo tempo homenagear essa "bússola", mas, sobretudo, percebê-la na contemporaneidade, com 
DOI: $10.12957 / \mathrm{e}-\mathrm{mosaicos} .2021 .53751$

potencialidades e com limitações vivenciadas por professores de Arte que a utilizam em suas salas de aulas.

\section{O ensino de ARTe e A polivalênCia}

Os anos de carreira no magistério exigem inúmeras reinvenções docentes devido à organicidade da sala de aula, o devir dos materiais pedagógicos que auxiliam o ensinoaprendizado dos alunos e as mudanças culturais que trazem novos perfis docentes. Também modulam essa reformulação as mudanças legislativas que organizam os sistemas de ensino.

A Abordagem Triangular teve sua estreia e repercussão entre arte-educadores enquanto vigorava nas escolas a LDB/1971, que instituiu a obrigatoriedade da disciplina sob nome "Educação Artística", além de criar o perfil polivalente do professor de Arte, formado em licenciatura curta com apenas dois anos de duração, opção emergencial disponível à época para alocá-los nas escolas - quem desejasse concluir a licenciatura plena deveria permanecer os quatro anos na graduação.

Logo, todas as modificações que hoje são vigentes no sistema de educação no Brasil vieram depois da divulgação da Abordagem Triangular ao grande público: LDB/1996, PCN-Arte, DCN, BNCC, além de outros dispositivos legais que alteram a nova Lei de Diretrizes e Bases, como a Lei 13.278/2016. Esta última alterou o artigo vinte e seis da LDB 9394/96, instituindo para o ensino da Arte quatro linguagens artísticas específicas e obrigatórias na Educação Básica: Artes Visuais, Música, Teatro e Dança.

Por sua vez, nem sempre leis sancionadas modificam realidades educacionais. No município de Teresópolis- $R \mathrm{~J}$, os concursos públicos continuam generalistas, com formato polivalente: a mesma prova contém questões das quatro linguagens artísticas. Isso significa dizer que, nas escolas de Ensino Fundamental II, pode haver docentes com qualquer uma das quatro formações acadêmicas trabalhando sob mesmo espaço, lecionando a disciplina Arte. E, certamente, este é apenas um exemplo de resquícios da polivalência dos muitos existentes no país.

A observação do dia a dia escolar ao longo de doze anos da professorapesquisadora foi oportuna para trocas de experiências entre docentes de linguagens artísticas distintas, percebendo que o uso de imagens do campo artístico é presente, também, nas aulas de professores com formação acadêmica em Música e Artes Cênicas. A condição de trabalho do professor de Arte em ambientes de ensino com estilhas polivalentes na atualidade, ainda, nos inquieta, por considerarmos que lecionar uma disciplina sem a formação acadêmica específica impacta o chão da escola em muitos sentidos: pela queda na qualidade do trabalho docente, que desconhece as metodologias de uma área que não é a sua; pela desvalorização das próprias disciplinas, que podem ser lecionadas por "qualquer um"; pela lacuna deixada ao aluno de uma experiência autêntica

30 ANOS DA ABORDAGEM TRIANGULAR: CONTRIBUIÇÕES DOS DOCENTES DE ARTE DO 248 
DOI: $10.12957 /$ e-mosaicos.2021.53751

da disciplina proposta, com todos os instrumentos e técnicas disponíveis ao professor formado.

A partir da percepção do uso da imagem pelo docente de Arte em diferentes linguagens artísticas adveio o questionamento de pesquisa desenvolvido no Mestrado Profissional em Práticas de Educação Básica, no Colégio Pedro II: como a Abordagem Triangular pode contribuir à prática das linguagens artísticas no ensino de Arte na Rede Pública Municipal de Teresópolis-RJ, abarcando potencialidades e limitações de seu uso na sala de aula.

A princípio, apoiada em leituras prévias à pesquisa em campo, por hipótese, considerou-se que a Abordagem Triangular fosse mais conhecida por docentes de Artes Visuais do que nas outras linguagens artísticas. Entretanto, docentes de Teatro, Música e Dança também poderiam utilizá-la, ressignificada pelo professor em suas metodologias de ensino, às vezes, mesmo sem intencionalidade.

Uma particularidade do Mestrado Profissional é seu caráter de pesquisa aplicada, constituindo-se como produção acadêmica voltada a questões referentes ao contexto de ensino, que, embasadas por literatura do tema escolhido, resulte como trabalho de conclusão uma dissertação e um produto educacional.

A pesquisa buscou, por conseguinte, compreender o perfil docente em relação à teoria proposta por Ana Mae Barbosa: se conhecem a Abordagem Triangular; onde conheceram; como usam os componentes triangulares; quais materiais pedagógicos são empregados; se a abordagem é pertinente às demandas atuais de sua própria disciplina; se sua conceituação teórico-prática se adequa às quatro linguagens artísticas previstas na LDB de 1996; quais potencialidades ela confere ao ensino de Arte na pós-modernidade e quais limitações interferem em seu uso no contexto escolar.

A elaboração do produto educacional "Uma bússola, vários caminhos: Caderno de Atividades com sugestões para utilizar a Abordagem Triangular nas aulas de Arte", vinculado à pesquisa aqui relatada, foi desenvolvido após aplicação do questionário com os docentes de Arte da Rede Pública Municipal de Teresópolis, pois a compreensão da Abordagem Triangular na contemporaneidade, ou seja, 30 anos após a publicação do livro que a difundiu entre professores de Arte e espaços de educação formal e não formal pelo Brasil, requer que estes profissionais sejam ouvidos em suas considerações laborais, pois são eles que vivenciam o dia a dia de uma sala de aula no segundo segmento da Educação Básica, foco da pesquisa.

A metáfora da bússola - utilizada para ilustrar como a Abordagem Triangular configura-se como propositora de múltiplos caminhos, apesar de apontar um norte ao ensino de Arte aos professores - foi inspiração poética presente no texto de Regina Machado (2010). A esse delineamento também contribuíram para o referencial teórico da 
DOI: $10.12957 / \mathrm{e}-\mathrm{mosaicos} .2021 .53751$

pesquisa a afirmação da Abordagem Triangular ser "teoria aberta" (AZEVEDO, 2014), e, portanto, receptível a novas interpretações e olhares.

\section{O caminho da pesquisa: a Abordagem Triangular como uma bússola atual}

A pesquisa foi estruturada como estudo de caso com abordagem qualitativa, envolvendo amostra de doze professores de Arte efetivos da Rede Pública Municipal de Teresópolis-RJ, que responderam a 45 questões de um questionário semiaberto, analisadas à luz da Análise do Conteúdo (BARDIN, 2011; FRANCO, 2007), por meio de duas categorias formadas dos rearranjos das questões no instrumento de coleta de dados: "Perfil, Interpretações e Reflexões Docentes: potencialidades e limitações" e "Metodologias e Experiências Docentes: potencialidades e limitações".

Apesar de a amostra não representar o cômputo total de professores de Arte da Rede Pública Municipal de Teresópolis-RJ, o número abarca mais da metade desses profissionais concursados na atualidade. Relevante, também, foi constatar que a amostra docente representou $80 \%$ das escolas de segundo segmento da rede de ensino pesquisada, entre unidades urbanas e da zona rural do município.

A opção em pesquisar, apenas, professores estatutários baseou-se na tentativa de conferir aos dados maior fidedignidade, pois o docente efetivo possui vínculo mais longo com a instituição de ensino do que aqueles sob regime de contrato temporário, o que se confirmou na análise de dados. A amostra foi composta por professores com tempo variado no magistério, compreendendo profissionais no início da carreira e outros já em fase de aposentadoria: de 8 a 33 anos de prática docente.

O perfil de formação acadêmica apontou que $67 \%$ dos docentes têm formação em Artes Plásticas, História da Arte e Artes Visuais, portanto, a linguagem visual tem maior abrangência entre as quatro linguagens artísticas, como pode ser observado na Figura 1.

Fig.1 - Perfil da formação acadêmica da amostra da pesquisa.

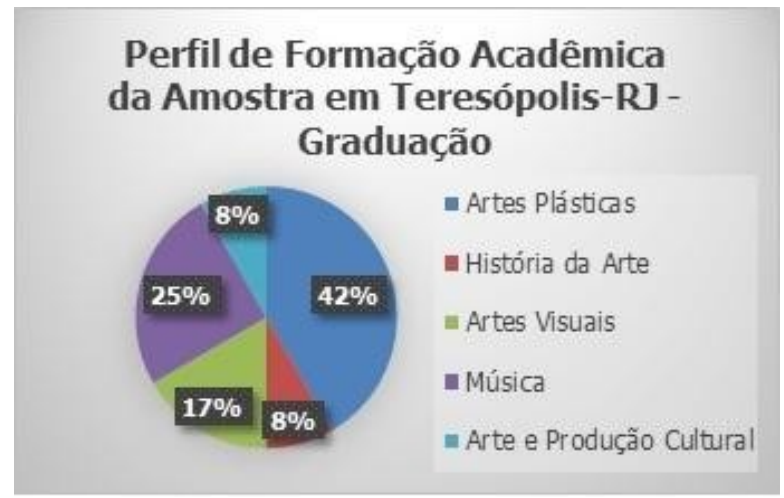

Fonte: as autoras. 
DOI: $10.12957 /$ e-mosaicos.2021.53751

Essa informação corrobora um dado fornecido por Iavelberg (2015), acerca dos números de licenciados em Arte, lecionada na disciplina pelas cinco regiões do Brasil. Baseada no Censo Escolar de 2012, a autora mostrou que Artes Visuais continha o maior número de professores atuando nas escolas brasileiras, seguido de Música, Teatro e Dança. Portanto, não foi incomum encontrar a área de Artes Visuais em maior evidência na amostra docente em Teresópolis-RJ. É um reflexo do panorama nacional da distribuição de professores de Arte pelo Brasil, insuficiente para contemplar todas as linguagens que a Lei 13.278/2016 determinou, ao modificar a LDB/96, sobretudo em Teatro e em Dança. Isso reflete, em parte, que as políticas nacionais para o ensino em Arte no Ensino Superior acabam nem sempre produzindo os efeitos esperados nas escolas da Educação Básica.

Em Teresópolis-RJ, por exemplo, o primeiro segmento da Educação Básica não possui ensino de Arte lecionado por professor formado na área; o conteúdo é ministrado pelo mesmo professor regente da turma, com formação em Nível Médio, na modalidade Normal, conforme edital do último concurso público realizado em 2011. Já, no segundo segmento, campo de estudo da pesquisa relatada, como não houve até o momento concurso público específico por linguagem artística, os aprovados podem ser de uma das quatro linguagens artísticas. Vale ressaltar que, na amostra, não houve docente com formação em Artes Cênicas e em Dança, ficando as duas linguagens sem análise quanto à aplicabilidade da Abordagem Triangular no ambiente escolar.

A primeira informação importante obtida com a pesquisa é que, entre os 12 professores pesquisados, todos demonstraram conhecer a Abordagem Triangular. Eles foram questionados sobre onde conheceram a teoria, sendo a Universidade o local mencionado por 10 entre 12 pesquisados. Já, cursos preparatórios para concurso público foram mencionados por dois professores, um concomitante à graduação. Por fim, um docente disse ter conhecido por pesquisa pessoal. Sendo o espaço universitário o local de ciência da Abordagem Triangular pela grande maioria da amostra, pode-se deduzir que a teoria é uma base adotada nas licenciaturas como abordagem contemporânea para o ensino de Arte no Brasil.

$\mathrm{Na}$ amostra pesquisada, há três professores formados em música, e dois responderam terem conhecido a Abordagem Triangular na faculdade, o que nos leva a considerar que sua adequação teórico-prática é interdisciplinar, estando essa percepção no currículo de licenciaturas em música. Ademais, 11 professores afirmaram que a Abordagem Triangular pode ser utilizada em qualquer linguagem artística.

Outra informação relevante foi perceptível, ao analisar as idades dos pesquisados, em 2019, remetendo-as ao ano de 1991, data da publicação da primeira edição do livro "A Imagem no Ensino da Arte", conforme Figura 2. 
DOI: $10.12957 / \mathrm{e}-\mathrm{mosaicos} .2021 .53751$

Fig.2 - Idade da amostra na publicação da obra "A imagem no Ensino de Arte".

\begin{tabular}{|ccc|}
\hline $\begin{array}{c}\text { Idade do } \\
\text { pesquisado } \\
\text { (em 2019) }\end{array}$ & $\begin{array}{c}\text { Tempo de publicação } \\
\text { da Abordagem } \\
\text { Triangular em 2019 }\end{array}$ & $\begin{array}{r}\text { Idade do pesquisado em 1991, } \\
\text { ano da publicação do livro } \\
\text { "A Imagem no Ensino da Arte" }\end{array}$ \\
\hline 34 & 28 & $\mathbf{6}$ \\
\hline 36 & 28 & $\mathbf{8}$ \\
\hline 38 & 28 & $\mathbf{1 0}$ \\
\hline 49 & 28 & 21 \\
\hline 33 & 28 & $\mathbf{5}$ \\
\hline 36 & 28 & $\mathbf{8}$ \\
\hline 48 & 28 & 20 \\
\hline 56 & 28 & 28 \\
\hline 38 & 28 & $\mathbf{1 0}$ \\
\hline 39 & 28 & $\mathbf{1 1}$ \\
\hline 40 & 28 & $\mathbf{1 2}$ \\
\hline 34 & 28 & $\mathbf{6}$ \\
\hline
\end{tabular}

Fonte: as autoras.

Em 1991, 09 professores eram crianças na faixa etária entre 05 e 12 anos de idade e, portanto, alunos do renomeado $1^{\circ} \mathrm{grau}$, época em que o ensino de Arte era chamado "Educação Artística" e influenciado pelas tendências tradicional, tecnicista e expressionista. Como afirma Ferraz e Fusari (1999, p. 43), "hoje, as aulas de Arte apresentam influências das três pedagogias enunciadas - tradicional, novista e tecnicista - em maior ou menor grau. Estas pedagogias, embora descritas separadamente, na prática se imbricam".

À época, faziam parte das atividades realizadas nas aulas de Educação Artística desenhos livres, influenciados pelo modernismo, nos quais a criatividade individual do aluno não deveria ter interferência do professor; desenhos prontos para colorir; desenhos feitos da observação realística de um modelo, entre outros exercícios do âmbito, apenas, da produção. Não se falava em História da Arte, por exemplo.

Entretanto, os nove professores da amostra também eram alunos no momento da promulgação da LDB/1996 e foram impactados pelas mudanças promovidas por ela no sistema de ensino brasileiro e no ensino da Arte, nomenclatura que substitui Educação Artística. Tardif (2012) diz que a formação do professor é heterogênea, socialmente construída, e não abarca somente os conteúdos de sua profissão em particular. A história de vida desses sujeitos está imbricada em suas formações profissionais, por meio de lembranças de quando eram alunos, de suas concepções subjetivas e de suas relações sociais.

Como o intuito da pesquisa era analisar a interpretação da Abordagem Triangular e seu respectivo uso nas salas de aulas na atualidade, pela ótica dos professores de Arte, os pesquisados foram indagados se a proposta de Ana Mae Barbosa seria usada mais facilmente em alguma das quatro linguagens, ou seja, por Artes Visuais, Música, Teatro ou 
DOI: $10.12957 /$ e-mosaicos.2021.53751

Dança. Cabe reforçar que o ambiente pesquisado é a escola, e nem sempre a estrutura física dispõe de espaços específicos para a prática artística, como sala de Arte, sala com isolamento acústico para música, sala ampla e sem mobília para teatro ou dança.

A pesquisa revelou, na análise dessa questão, que os professores consideraram que a Abordagem Triangular não favorece uma única linguagem artística. No plano teórico, por sua vez, explanaram o caráter adaptável dos vértices triangulares, cabendo ao professor ressignificá-los às demandas de sua linguagem e das metodologias de ensino.

\section{3 - OS VÉRTICES DO TRIÂNGULO: LER, CONTEXTUALIZAR, FAZER}

A literatura sobre Abordagem Triangular, como o nome revela, apresenta uma diretriz conceitual de ensino de Arte, baseado em três ações interligadas e não hierárquicas, podendo a tríade ler, contextualizar, fazer ser experimentada em outras sequências, desde que haja a triangulação, condição para a epistemologia da Arte, segundo Ana Mae Barbosa. Portanto, não propõe ordenamento das ações de leitura, contextualização e fazer artístico; elas se imbricam.

A pesquisa com os professores demonstrou compreensão da interdependência entre os vértices que estruturam a Abordagem Triangular. Entre as considerações apontadas sobre a questão, dois docentes manifestaram preferência pela triangulação na ordem "contextualizar, apreciar, fazer"; um reafirmou que a AT só faz sentido se seus três eixos são utilizados; outro expressou que a escolha pela ordem da triangulação não gera a aprendizagem imediata, vislumbrando o potencial de propor o conteúdo sob diferentes óticas. Houve, também, uma colocação dizendo que, apesar de serem eixos independentes, podem ser utilizados em graus distintos durante o processo. Observação pertinente, pois, apesar de serem três ações a serem realizadas, trianguladas, não precisam ser aplicadas com a mesma intensidade. A tônica do seu uso nas salas de aula dependerá do objetivo da atividade planejada pelo professor e da organicidade da turma.

Como vimos, em 2021, a primeira edição do livro "A Imagem no ensino da Arte" completa 30 anos. Por sua vez, ao longo desse tempo houve a promulgação da Lei de Diretrizes e Bases da Educação em 1996, dos Parâmetros Curriculares Nacionais, das Diretrizes Curriculares Nacionais, do Plano Nacional de Educação e, por fim, da Base Nacional Comum Curricular. Tais dispositivos legais modificaram orientações nacionais para a educação nacional, logo, para o ensino da Arte nas escolas. Ter pesquisado a pertinência dos pressupostos da Abordagem Triangular na contemporaneidade das salas de aulas, por meio da figura docente, permitiu compreender como a diretriz teóricoprática está ressignificada, utilizada diante desse cenário, pós 1991.

Os professores pesquisados consideraram que a Abordagem Triangular possui caráter atual para as demandas que o ensino de Arte requer na pós-modernidade, 
DOI: $10.12957 / \mathrm{e}-\mathrm{mosaicos} .2021 .53751$

compreendida a partir de 1980 até os dias atuais, segundo Iavelberg (2015). Disseram, também, que a utilizam frequentemente em sua prática escolar.

Sobre cada componente separadamente que estrutura a Abordagem Triangular, os pesquisados foram questionados quanto à importância para o ensino da Arte e o respectivo uso em sala de aula.

Sobre o vértice triangular destinado à leitura de imagens, a amostra foi unânime ao afirmar que é importante trabalhar nas aulas de Arte com leitura de obras de Arte e/ou imagens de outros códigos culturais. Interpretação idêntica foi assinalada ao concordar que ensinar a ler imagens é uma maneira de promover alfabetização visual e, por conseguinte, ajudar o aluno na compreensão das visualidades culturalmente construídas no mundo, não se limitando ao universo artístico. Essa importância interpretativa conferida ao eixo leitura foi comparada ao uso efetivo em sala de aula, sendo afirmado por doze pesquisadores: nove disseram utilizar frequentemente e três, sempre.

A presença da imagem na sala de aula na disciplina Arte deixou de ser tabu entre a classe do magistério, ao menos para a amostra. Ana Mae Barbosa (1994) disse em "A Imagem no Ensino da Arte" que a desconfiança na utilização de imagens de obras de Arte e da Cultura Visual (como o exemplo da TV) era manifestada até em cursos de pósgraduação para docentes de Arte durante os anos 1980.

Na contemporaneidade, a imagem não somente é utilizada nas aulas, mas teve seu repertório de leituras visuais, ampliado pelos professores que continuam sendo os responsáveis por suprir suas aulas com materiais diversificados, caso queiram ampliar seu universo pedagógico. Entre os materiais pedagógicos utilizados, o livro didático não foi apontado como fonte mais utilizada nas aulas, estes abrangem diferentes plataformas imagéticas, como reproduções, jogos e livros diversos, além de vasta gama de equipamentos tecnológicos, como vídeos, tablet, celular, grupos no WhatsApp, slides, Datashow, aproximando a aula de Arte ao mundo da Cultura Visual, além de música ao vivo. A ida aos museus ou similares foi citada poucas vezes, comprometida por fatores escolares (tempo, logística, distância, custo).

Fig.3 - Recursos utilizados na leitura de imagens pelos docentes da amostra.

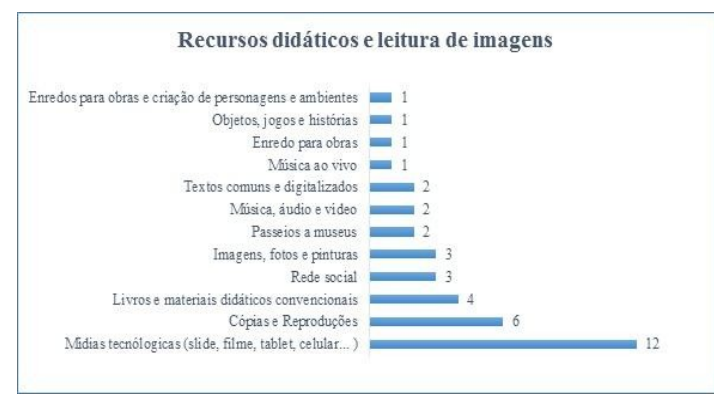

Fonte: as autoras 
DOI: $10.12957 /$ e-mosaicos.2021.53751

O chão da escola manifesta outra relação particular com o Triângulo: a contextualização. As salas de aulas podem comportar 40 alunos no segundo segmento e todos precisam estar incluídos nas atividades propostas, individualmente ou em grupos. A recepção em participar das atividades nem sempre é unânime, por coexistir no mesmo espaço diferentes interesses, que, muitas vezes, não será na atividade proposta. Houve dois relatos docentes, mostrando que os alunos se interessaram mais nas aulas quando houve aproximação do conteúdo explicado ao seu contexto ou realidade.

A contextualização, quando realizada em um primeiro momento de forma geral para toda turma, pode continuar ocorrendo individualmente quando o fazer discente acontece. Isso porque, ao percorrer a sala de aula mediando a atividade, acontecem diálogos entre os próprios alunos, ou entre estes e o docente, estendendo as informações prévias e incorporando-as com outras provenientes da conversa. Há, pois, contextualização na ação do fazer artístico e no processo de análise da imagem estudada. Compreendemos ser esse o ziguezague dito por Barbosa ao dinamizar a metáfora do triângulo (2014).

A contextualização histórica para o ensino de Arte é vista como importante para os docentes pesquisados, pois possibilita ao aluno compreender os diferentes contextos de uma obra de Arte e como está relacionada às questões sociais de cada época, permitindo diferentes apreensões estéticas do processo criativo, além de entender a produção artística como conhecimento sócio-histórico.

Os meios utilizados na contextualização variam conforme metodologia do professor, podendo ser via textos impressos sobre História da Arte, explanação oral, observando imagens, correlacionando períodos e produções artísticas, fazendo analogias com a contemporaneidade e desta com o passado, propondo situações hipotéticas com os alunos, solicitando pesquisas, levando vídeos, slides, músicas, inclusive, partindo das próprias criações discentes. Essa variedade de opções atribui dinamicidade à História da Arte, democratizando seu pertencimento nas escolas públicas, mas não como adorno de apreciação romântica, pois como propõe Ana Mae Barbosa (2014, p. 39) "analisar as características formais do objeto no seu habitat de origem não pode ser o escopo máximo da história da Arte. Cada geração tem o direito de olhar e interpretar a história de uma maneira própria".

O fazer artístico é apontado como o vértice triangular que acaba sobressaindo na sala de aula, não por importância hierárquica entre os três, mas por alguns fatores pedagógicos, tais como: a preferência desse momento para os alunos (pelo aspecto lúdico, pelo uso de materiais diferentes, ou mesmo pelo gosto discente) e relação com fatores do sistema escolar (expectativa de notas). Alguns docentes disseram que a questão do fazer sobressair é relativa, pois depende do foco que o professor quer dar à aula, dos materiais disponíveis, da relação professor-aluno, do tempo de aula, além do próprio fazer ser mediado por leitura e por contextualização. 
DOI: $10.12957 / \mathrm{e}-\mathrm{mosaicos} .2021 .53751$

A cópia de modelos pré-existentes e a livre-expressão não foram consideradas como melhores tendências pedagógicas no ensino de Arte. Sobre a releitura, um dos pontos cruciais de interpretação equivocada da Abordagem Triangular, segundo Barbosa (2010, p. 15), ao justificá-la como "uma das possibilidades do fazer, este sim uma ação básica", reler uma obra/imagem não foi considerada cópia da matriz visual observada, e sim uma nova interpretação, um "novo olhar", como dito na amostra. Entre outras observações, houve relato docente em não ser adepto dessa opção do fazer artístico, reforçando ser apenas um dos caminhos possíveis, e caso seja usado, pode ser dialogada com outros contextos.

Fig. 4 - Releitura da obra de Sebastião Salgado, com base no Realismo e no contexto das lavouras da cidade. Foto produzida por aluno do $9^{\circ}$ ano, da rede municipal de Teresópolis.

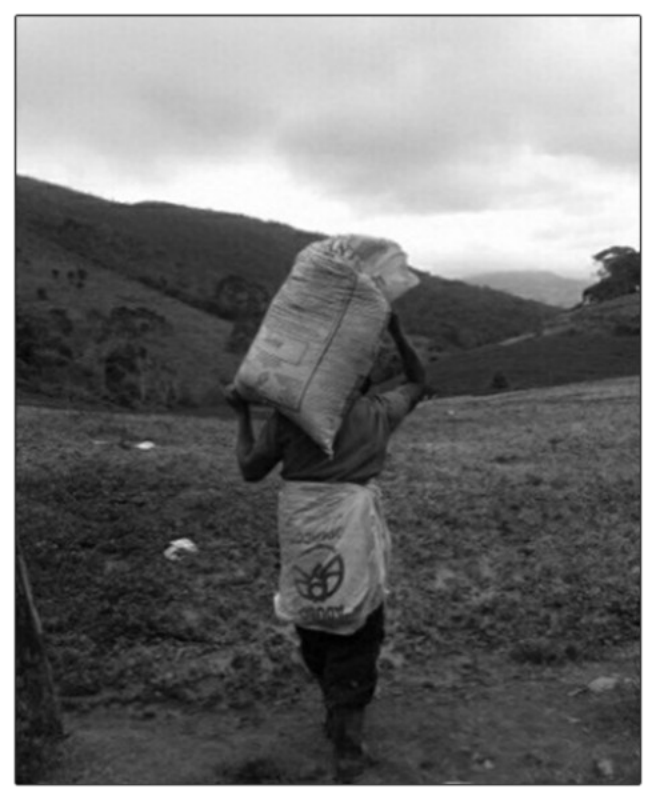

Fonte: Acervo da pesquisadora Maria Gabriela da Silva

Entretanto, para alguns os alunos ainda permeiam preferências práticas por copiar modelos pré-existentes ou conceber a aula de Arte apenas para desenhar, nem sempre compreendendo a relação entre Arte e conteúdo. A maioria dos professores respondeu em seus questionários que a frase "pensei que Arte fosse só desenhar e pintar" já foi dita por seus alunos. Oito docentes relataram ser mais ouvida no Sexto Ano; três docentes indicaram o Nono Ano e, apenas, um professor disse nunca ter ouvido. Como a disciplina Arte ainda não está presente no primeiro segmento na Rede Pública Municipal de Teresópolis-RJ, com professor específico em Arte, estando diluída entre as matérias e a cargo do professor generalista desse segmento (formado em Pedagogia), essa exclamação discente expressa um ensino distante das prerrogativas da educação pós-moderna para o ensino de Arte e, portanto, do que propõe a Abordagem Triangular. Evidencia uma prática Arte-educativa próxima das Pedagogias Tradicional e Nova. 
DOI: $10.12957 /$ e-mosaicos.2021.53751

\section{CONSIDERAÇõES FINAIS - POTENCIALIDADES E LIMITAÇõES}

As potencialidades analisadas a partir da pesquisa indicam como fundamental a participação do olhar discente e suas vivências no processo de ensino-aprendizado em Arte, estabelecendo uma relação dialogal entre educador-educando. A variedade de recursos didáticos, inclusive os tecnológicos, atraem mais a atenção dos alunos. A triangulação "ler, contextualizar, fazer" sem única sequência de utilização, além da História da Arte poder ser abordada de forma dinâmica, sem estar necessariamente na linearidade dos acontecimentos, são fortes aliados dos professores, que podem programar suas aulas de forma múltipla e criativa.

Os problemas enfrentados na prática escolar ao usar a Abordagem Triangular não foram apontados como intrínsecos à conceituação triangular em si, mas por fatores externos a esses pressupostos. Tais fatores, como indisciplina discente, defasagem etária versus série escolar, estrutura física e tempo das aulas são algumas das "variáveis" que submetem à utilização da Abordagem Triangular na prática escolar limitações de seus potenciais epistemológicos.

Ainda na atualidade, é relatado pelos professores que a disciplina Arte ainda traz estereótipos de um passado remanescente quando se chamava Educação Artística, como a visão de que sua função na escola seria de recreação, passatempo, decoração de mural, ensino de técnicas, sendo um saber secundário, de menor importância no currículo.

Visando a minimizar essas limitações e a oferecer uma proposta de material didático útil à prática docente, esta pesquisa foi concluída com a construção de um produto educacional. Assim, após a realização da pesquisa em campo com 12 professores de Arte efetivos da rede pública municipal de Teresópolis-RJ, suas considerações sobre usos/interpretações da Abordagem Triangular foram analisadas e moldaram a elaboração das quatro atividades propostas no produto educacional. "Uma bússola, vários caminhos: Caderno de Atividades com sugestões para utilizar a Abordagem Triangular nas aulas de Arte" foi pensado para ser um aporte pedagógico para professores de Artes e outras áreas que queiram descobrir na prática um pouco mais da Abordagem Triangular por meio atividades práticas sugeridas ao segundo segmento da Educação Básica.

A organicidade da sala de sala, espaço de convivência de tantas heterogeneidades, possui inúmeras potencialidades e persistentes limitações. A construção de um produto educacional, baseado na Abordagem Triangular foi a forma encontrada pelas pesquisadoras de propor um material didático que visa a auxiliar docentes de Arte, com distintas formações e experiências, a se nortearem em quatro atividades. Sem caminhos restritos ou mapas detalhados, mas com um instrumento em mãos que indica por onde podemos navegar. 
DOI: $10.12957 / \mathrm{e}-\mathrm{mosaicos} .2021 .53751$

\section{REFERÊNCIAS}

AZEVEDO, Fernando Antônio Gonçalves de. A Abordagem Triangular no ensino das Artes como teoria e a pesquisa como experiência criadora. 207f.: il.; $30 \mathrm{~cm}$. Tese (Doutorado em Educação). Recife: O autor, 2014.

BARBOSA, Ana Mae. Arte-educação: conflitos/acertos. São Paulo: Max Limonad, 1984.

. A imagem no ensino da Arte. Anos oitenta e novos tempos. $2^{a}$ ed. São Paulo: Editora Perspectiva, 1992.

. A imagem no ensino da Arte: Anos 1980 e novos tempos. 9a ed. São Paulo: Editora Perspectiva, 2014.

BARDIN, Laurence. Análise de Conteúdo. São Paulo: Edições 70, 2011.

BRASIL. Lei Federal 9394 de 20 de dezembro de 1996. Estabelece as diretrizes e bases da educação nacional. Disponível em: http://portal.mec.gov.br/seesp/arquivos/pdf/lei9394_Idbn1.pdf. Acesso em: 19 fev. 2019.

. Lei Federal 13278 de 02 de maio de 2016. Altera o § $6^{\circ}$ do art. 26 da Lei no 9.394, de 20 de dezembro de 1996, que fixa as diretrizes e bases da educação nacional, referente ao ensino da Arte. Disponível em: http://www.planalto.gov.br/ccivil_03/_Ato2015-2018/2016/Lei/L13278.htm. Acesso em: 19 fev. 2019.

FERRAZ, Maria Heloísa Corrêa de Toledo; FUSARI, Maria F. de Rezende e. Metodologia do Ensino de Arte. 2 ed. São Paulo: Cortez, 1999.

FRANCO, Maria Laura Publisi Barbosa. Análise de Conteúdo. $2^{\mathrm{a}}$ ed. Brasília: Liber Livro Editora, 2007.

IAVELBERG, Rosa. Arte-educação modernista e pós-modernista: fluxos. Tese de livre docência. Faculdade de Educação da Universidade de São Paulo. São Paulo: s.n., 2015.

MACHADO, Regina Stela. Sobre mapas e bússolas: apontamentos a respeito da Abordagem Triangular. In: BARBOSA, Ana Mae; CUNHA, Fernanda Pereira da (orgs.). $A$ Abordagem triangular no ensino das Artes e culturas visuais. 1a ed. São Paulo: Cortez, 2010. P. 64-79. 
DOI: $10.12957 / \mathrm{e}-\mathrm{mosaicos} .2021 .53751$

TARDIF, Maurice. Saberes Docentes e Formação Profissional. 14 ed. Petrópolis, RJ: Vozes, 2012.

Recebido em 13 de agosto de 2020

Aceito em 08 de março de 2021

A e-Mosaicos Revista Multidisciplinar de Ensino, Pesquisa, Extensão e Cultura do Instituto de Aplicação Fernando Rodrigues da Silveira (CAp-UERJ) está disponibilizada sob uma Licença Creative Commons - Atribuição - NãoComercial 4.0 Internacional.

Os direitos autorais de todos os trabalhos publicados na revista pertencem ao(s) seu(s) autor(es) e coautor(es), com o direito de primeira publicação cedido à e-Mosaicos.

Os artigos publicados são de acesso público, de uso gratuito, com atribuição de autoria obrigatória, para aplicações de finalidade educacional e não-comercial, de acordo com o modelo de licenciamento Creative Commons adotado pela revista. 